Frequently ulceration is an early symptom; it may result in complete disappearance of the neoplasm. Icterogen makes no difference in the appearance of the macrophage in the tumour's surroundings. The macrophage invariably shows a distinct bile stain, easily preserved in microscopic specimens by rapid fixation and early histological preparation.

I have not lost sight of the fact that icterogen is a powerful toxic agent producing widely extended circulatory trouble and damage in the liver. Under such conditions, it may well be argued, it is not astonishing to find in the animal, as a sequel of general malnutrition, an inhibition or even degeneration of a tumour graft. But it has not been my intention to advocate an icterogen cure of malignant growths. I merely endeavoured to prove that by damage to the liver the tumour also suffers, probably through the want of material needful for its growth. If so, then we have a new field of therapeutical cancer research thrown open to us. It would, indeed, be of greatest interest were we able to establish a scientific basis for the experience gathered by our medical forefathers, that amongst all inorganic agents used in the treatment of malignant growths none has ever equalled arsenic, whose specific effects on the liver have been so frequently". and widely proved, whose curative influence on cancer has but recently again been advocated.

\section{A CASE OF LIGNEOUS THYROIDITIS. ${ }^{\mp}$}

By GEORGE R. MURRAY, M.A., M.D. CANTAB, D.C.L. DURH., F.R C.P. LOND

PROFESSOR OF MEDICINE IN THE UNIVERSITY OF MANCHESTER; PHYSIOLAN TO THE MANCHESTER ROYAL INEIRMARY; AND

FREDERICK A. SOUTHAM, M,A., M.B. OxoN., F.R.C.S. ENG.,

EMERTYUS PROFESSOR OF SURGERY IN THE UNIVERSITY OF MANCHESTER; . CONSULTING SURGEON TO THE MANCHESTER ROYAL INFIRMARY.

IIGNEOUs thyroiditis, or Riedel's disease, is an uncommon malady, and therefore we consider it worth while to give a short account of a case which has recently come under our observation. The disease was originally described by Riedel ${ }^{2}$ in 1896 as " Eisenharte Strumitis," but we have not seen his original paper. Three cases are described by Mr. James Berry ${ }^{3}$ in bis well-known book as examples of "primary chronic inflammation of the thyroid gland." Recently a full account of the subject has been given by $X$. Delore and H. Alamartine, ${ }^{4}$ in which short histories of 13 published cases are given, in addition to the details of one case observed by the authors.

The patient, a male, aged 23 years, was brought to us by Dr. E. Perkins on July 11th, 1911, with the following history. For about 18 months he had noticed that his neck was gradually becoming somewhat swollen, and during the last two or three months the enlargement had increased more rapidly, his voice and breathing also becoming affected. Latterly the pressure symptoms had become much exaggerated, respiration at times being attended with great difficulty, so that at night he was often unable to lie down, relief being only obtained by sitting up in bed and bending the head forwards. The dyspnoea was paroxysmal and increased on any exertion, respiration being attended by stridor, at times so loud as to be heard in an adjoining room.

O 1 examining the neck a well-marked uniform enlargement of both lobes of the thyroid gland was found to be present. The swelling was unusually firm in consistence, with a smooth surface, and somewhat fixed, so that it moved very slightly on deglutition. Its nature was rather obscure, as it did not present the symptoms of an ordinary goitre, the fixity and density suggesting the possibility of the early stage of malignant disease. As the symptoms were rapidily becoming urgent, and it was evident that relief would soon be required by surgical interference, it was resolved to explore the swelling without delay, and, if possible,

I A paper read at a meeting of the Pathological Society of Manchester on April 24 th, 1912

2 Die chronische zur Bildung elsenharter Tumoren führende Entzuindung der Schilddrise, Verhandlungen der Deutschen Gesellschaft fir Chirurgie, Berlin, 1896, Band i., p. 101

3 Diseases of the Thyroid Giand, p. 137.

4 La Thyroidite Ligneuse (Maladie de Riedel), Revue de Chirurgie, tome xliv., p. 1, July, 1911. remove the isthmus and one lateral lobe; if, however, this was found to be impracticable, then to perform tracheotomy.

The patient accordingly went into a nursing home, and the operation was performed on July 26th, our colleague, Mr. J. Howson Ray, very kindly assisting, and the anresthetic being administered by Mr. Alexander Wilson. As there was no difference in the size of the two lobes, it was decided, if possible, to remove the right lateral lobe and isthmus, which were exposed by the ordinary " collar" incision, commencing on the right side of the neck and continued beyond the middle line. After dividing the integument, it was found that the overlying muscles and fascia were adherent to the outer surface of the thyroid, the glandular tissue, capsule, and adjacent structures being converted into dense, apparently fibrous tissue, of a whitish colour, and of such hard consistence that it was not easy to cut it with a scalpel. On making an exploratory incision into the exposea lobe it presented the same structure throughout, all trace of glandular tissue having completely disappeared, and a similar condition was found in the isthmus. A wedge-shaped piece of the gland, consisting of the inner portion of the right lobe, together with the isthmus were first excised, very little hæmorrhage attending the process. Then successive layers were removed from the remaining portion of the same lobe until its periphery was approached, when the bleeding became more profuse, and somewhat difficult to arrest, in consequence of the dense tissue in which the vessels lay. As the trachea was extremely narrowed laterally, presenting the appearance described as "scabbard" trachea-in order completely to remove the lateral pressure on both sidesit was thought advisable also to excise the greater part of the left lobe, and this was dealt with in a similar manner.

Though the trachea was now completely exposed and relieved of all lateral pressure, there was still marked obstruction to the respiration. This was found to be due to a definite band of dense tissue, extending from the tip of one lateral lobe to the other, and continuous with the lower border of the isthmus, which ran in front of the trachea, compressing it antero-posteriorly. This was cautiously cut through upon a director passed beneath it, its division relieving the trachea of all pressure, and being almost immediately followed by a distinct improvement in the breathing. All bleeding having been carefully arrested, the wound was closed, free drainage being provided by the insertion of two tubes-one on either side of the neck.

The after-history was uneventful, the patient making a rapid recovery from the operation : the pulse never rose above 84 , and the highest temperature was $99^{\circ} \mathrm{F}$. After the removal of the tubes on the second day the wound quickly healed, and the patient left the nursing home at the end of three weeks. The relief afforded by the operation was immediate and very marked, the dyspnoea at once ceasing and the voice rapidly improving.

The patient was seen again on Oct. 4th, when he complained of feeling cold. The face had changed in appearance owing to the development of some solid cedema of the subcutaneous tissues of the face and lips. There was also a red flush in each cheek, so that he had the characteristic facial appearance of an early stage of myxœdema. The skin generally was dry and rather rough, and he only perspired in the axillæ. The hair was dry, the voice was husky, and the tongue was slightly swollen. The memory had become rather defective. These symptoms clearly showed that he was suffering from secondary myxœedema which had developed after the partial thyroidectomy. He was treated with thyroid tablets, and when last heard of was in good health and doing his ordinary work.

Examination of microscopical sections prepared by Dr. W. Mair from the portions of the thyroid gland which had been removed showed that they contained no normal thyroid tissue. For the most part they consisted of dense fibrous tissue, some parts of which contained but few nuclei, while others were more richly nucleated and appeared to be more recent in origin. A few small collections of epithelial cells were found. In one case they were arranged in a row, partially inclosing a space which contained a small group of epithelial cells. At one part some areas-mostly oval in shape - were found, lined by fibrous tissue, and containing a homogeneous material which was probably colloid. No normal epithelial lining to these spaces could be distinguished, and they were separated from each other by dense strands of 
fibrous tissue. These areas were evidently the remains of degenerated alveoli, but no portion of glandular tissue which could have been functionally active at the time of its removal could be found. The general appearance of the sections closely resembled that presented by sections from the atrophied and fibrotic thyroid gland of an advanced case of myxodema.

The symptoms of this interesting disease are due to the progressive development in the thyroid gland of a dense fibrosis. This fibrosis may not only involve the capsule of the glard, but it may extend to the surrounding connective tissue and muscles. In Professor Jeannel's ${ }^{4}$ case the fibrous tissue involved the sheath of the vessels and nerves in the neck and extended up to the base of the skull. This tendency of the fibrosis to extend beyond the capsule of the gland serves to distinguish the condition from the chronic atrophic fibrosis which is found in myxoedema, as the latter does not extend beyond the gland itself. This tendency to extend into surrounding tissues accounts for the early compression of the trachea and dyspnoea, which are characteristic symptoms of Riedel's disease, but which do not occur in myrodema. As a rule, the destruction of the alveoli of the gland is not sufficiently extensive to induce myxoedema. Our case is of special interest in that the removal of a portion of the diseased gland, which apparently contained no normal tissue, was nevertheless sufficient in some way so to reduce the supply of the secretion that symptoms of myzœdema developed shortly afterwards.

Nothing so far is known of the cause of the disease, though the character of the microscopical changes suggest that it may be the result of some chronic infection. It occurs in both sexes and most commonly develops between 30 and 40 years of age, so that in our case the symptoms developed earlier than usual. The development of the disease is generally slow, but it may take place within a few months or even a few weeks. In some cases pain has been complained of in the affected gland and radiating to the ears and the back of the neck. Dyspnoea and stridor due to compression of the trachea, which is not displaced to one side or the other, are the most important symptoms, and notable because they are associated with a comparatively slight enlargement of the gland itself, which, however, becomes hard in consistence and fixed in position. The skin overlying the gland is not adherent and the lymphatic glands are rarely enlarged. The narrowing of the trachea may be accompanied by a laryngo-tracheitis, causing cough. One recurrent laryngeal nerve may be involved in the cervical cellulitis, causing paralysis of one vocal cord. It is thus evident that the disease is of great interest owing to the remarkable manner in which it may resemble the harder forms of malignant disease of the thyroid gland.

The following points are of value in distinguishing between the two diseases. Dysphagia, which is not ancommon in malignant disease, is rare in ligneous thyroiditis. The nniform enlargement of the gland, the early onset of severe dyspncea, the freedom of the skin from adhesion, the absence of enlargement of the lymphatic glands, and the earlier age at which it usually occurs are all in favour of chronic thyroiditis.

No medicinal treatment appears to exert any influence upon the progress of the disease. When once compression of the trachea has commenced, so that there is slight stridor with dyspncea on exertion, a sufficient amount of the diseased gland should be excised to free the trachea completely. No more tissue than is necessary for this purpose should, however, be removed, so that, if possible, a sufficient amount of secreting tissue may be left to prevent the onset of myxœdema. Delore and Alamartine state that $X$ rays have an almost specific action in Riedel's disease, and refer to one case recorded by $\mathrm{K}$. Silatschek and another under the care of M. Barjou, in which recovery followed the application of $X$ rays. It is difficult to understand how $X$ rays can be beneficial, as in Graves's disease they are actually employed to produce a fibrosis of the thyroid gland and they may also lead to the formation of adhesions between the capsule of the gland and the surrounding structures. We have had, however, no experience of this treatment in this disease, and consider it might be tried in an early case in which there were no urgent symptoms and there was no risk in postponing operation.

Manchester.

\section{THE TREATMENT OF MUSCULAR AND JOINT INJURIES BY GRADUATED CON'TRACTION.}

\author{
By MORTON SMART, M.B., СH.B. EDIN., \\ AND \\ W. ROWLEY BRISTOW, F.R.C.S. ENG.
}

IN the following paper an attempt is made to describe a method which we adopt for the treatment of muscular and joint injuries, and for the redevelopment of wasted muscles. The treatment consists in the stimulation of the muscles by means of an induced current, but it must be clearly understood that no virtue is claimed from the electricity per se. It is simply a means to an end, that end being muscular contraction with the restoration of muscle function.

The instrument we find most satisfactory is one with few turns in the primary and secondary windings, and therefore of low self-induction. It is so arranged that the degrees of contraction can be controlled by manipulation of the central core, in preference to the more usually adopted "sledge" method of control. The exact form of apparatus used is of little consequence, provided it can be controlled so as to produce a graduated contraction of the muscle-that is, minimal, submaximal, or maximal contractions.

Every muscle in the body is in a state of slight continued contraction-i.e., muscular tone--and if injured this condition of tone is at once altered. A strained muscle is relaxed, stretched, and inflamed, and so is incapable of complete voluntary contraction. In many cases this disability, primarily muscular, shows itself by impairment of the function of the joint on which the muscle normally acts. The other muscles which control movement of the joint act of necessity at a disadvantage, one of their number being thrown out of action. The result of this is that the joint is affected in two ways: firstly, by the original muscular strain ; and secondly, by the excessive strain caused to the other muscles, which work at a disadvantage without their fellow, and thus still further complicate the impairment of function in that joint.

The condition of impairment is the immediate result of a strain to a muscle or muscles which control the movement of a joint, and is of importance because the joint is liable to become further crippled owing to muscular wasting, the formation of adhesions, and the laxity of the whole structure caused by the absence of the normal muscular tone. That the seriousness of the early condition is not always realised is shown by the fact that following some slight injury-e.g., a sprain-one often gets a history of months of disability and pain, all of which could have been avoided if the secondary results had been prevented from supervening by the proper treatment of the condition from the first.

The type of contraction produced so closely simulates the physiological contraction of muscle that it is indistinguishable from a normal voluntary contraction. The contraction can be accurately controlled. Starting from zero, it may be gradually increased to the maximal contraction which the muscle acted on is capable of without damage, and the muscle may then be allowed to relax just as gradually.

A healthy group of muscles, when acted upon in this way, can be made to contract and relax rbythmically, so as to cause painless production of the movement of the joint on which they act. In order to describe the actual method of applying this form of treatment it will perhaps be best to describe the treatment of an actual case and then to generalise.

Take, for example, the treatment of a simple strain of the adductor longus mnscle, the so-called "rider's strain." The patient is placed on a couch with the lower extremities bare. One electrode is placed under the knee of the injured leg. The knee is slightly flexed, abducted, and externally rotated. The other electrode is held in the operator's left hand, gripped between the thumb and first finger, and is brought into contact with the addnctor longus. The electrode being in contact with the muscle, the muscle substance is grasped by the fingers and thumb of the hand, so that the amount of contraction may be felt. The operator's right hand controls the soft core of the coil, which is inserted and withdrawn rhythmically at a rate of about 60 times a minute. Each time the core is inserted the muscle contracts and vice-vers $\hat{\alpha}$, 